\title{
Saúde Mental em um Hospital Público: o Olhar de Profissionais Médicos do Município do Rio de Janeiro
}

\author{
HELOISA DOS REIS MALHEIRO MÁXIMO • \\ MARIA LÚCIA MAGALHÃES BOSI •
}

\section{RESUMO}

Este estudo teve por objetivo compreender percepções de médicos de um hospital público acerca do papel dos profissionais de Saúde Mental nesse espaço institucional, explorando interfaces estabelecidas entre as duas categorias no cotidiano da assistência, tal como percebidas pelos informantes. Para tanto, desenvolveu-se um estudo qualitativo fundamentado na tradição crítico-interpretativa como caminho metodológico, elegendo-se como técnica a entrevista não-diretiva. A amostra foi composta por médicos de diferentes setores que, no momento do estudo, haviam encaminhado pacientes para os profissionais de Saúde Mental e integravam a equipe do hospital por um período mínimo de dois anos. Com base nas categorias que emergiram no campo, a análise identificou diferentes temas, configurando uma rede interpretativa que representou a base do exercício hermenêutico. Os resultados do estudo apontam uma heterogeneidade no que se refere às concepções dos informantes acerca do papel da Saúde Mental no espaço hospitalar. No que tange à organização do trabalho, a variável tempo é fator fundamental no cotidiano do atendimento. Percebe-se uma nítida diferenciação entre o paradigma "psi", referente aos profissionais da Psicologia e da Psiquiatria, e o paradigma médico, revelando obstáculos para uma efetiva integração entre esses dois modelos.

Palavras-chave: Pesquisa qualitativa; profissionais de saúde; Saúde Mental; serviços de saúde; saúde pública.

Recebido em: 24/05/2006.

Aprovado em: 27/09/2006. 


\section{Introdução}

A presente investigação ${ }^{1}$ configura-se como um estudo de caso que objetivou compreender percepções de médicos de um hospital público, acerca do papel dos profissionais de Saúde Mental dessa instituição, explorando, simultaneamente, interfaces estabelecidas entre as categorias no plano da assistência, tal como percebidas pelos médicos informantes. Saúde Mental é uma denominação que, neste estudo, designa o campo de atuação "psi”, articulado no espaço dos hospitais gerais e de emergência pelos profissionais de Psicologia e de Psiquiatria, podendo, ainda, se incluir em suas bases de conhecimento, uma formação psicanalítica.

$\mathrm{O}$ interesse por esse objeto se deve à implantação, no hospital aqui focalizado, de um projeto pretensamente inovador em Saúde Mental, em consonância com a Reforma Psiquiátrica, por ocasião da mudança de espaço físico da unidade hospitalar em questão, concretizada em novo endereço e novo perfil de atuação frente à população. A mobilização, intensa e transformadora, foi percebida na instituição como um desafio a ser enfrentado: dos "tijolos" que desenhavam novos espaços aos debates sobre "recursos humanos" necessários para atender ao projeto que dava seus primeiros passos no cenário de um hospital de emergência (MÁXIMO, 1997).

Dentre as características que passam, então, a diferenciar este novo projeto em Saúde Mental do anteriormente instituído, podemos apontar: a continuidade das ações dos profissionais "psi" através da permanência em plantões noturnos e de fins de semana, levando em consideração a subjetividade dos pacientes; o trabalho de cunho interdisciplinar representado pelas trocas e encaminhamentos entre diferentes especialidades, sustentado pela ação sistemática das interconsultas; a atenção aos usuários de álcool e drogas, contribuindo para a diminuição do número de internações psiquiátricas em clínicas conveniadas, de acordo com o resultados do censo realizado em nossa cidade (FAGUNDES; LIBÉRIO,1997), que demonstrou ineficácia e abuso nessas internações.

Para além do marco histórico que a Reforma Psiquiátrica engendrou, produzindo efeitos no cuidado e na rede de assistência, cabe nos reportarmos, também, às modificações demarcadas pela VIII Conferência de Saúde, em 1986, que não só incentivou a criação do Sistema Único de Saúde (SUS), com vistas à assistência integral à saúde, descentralização e participação da comunidade, como trouxe em seu discurso a necessidade de incorporação de 
outros saberes além do saber médico. Nesse enfoque, outras profissões e especialidades, como as "psi", foram incluídas no cotidiano da "arena" clínica, passando a integrar as equipes dos hospitais, visando à facilitação na troca de experiências, pela diversidade de objeto de estudo das disciplinas envolvidas em relação ao processo saúde-doença.

Tal iniciativa, apesar de concebida como um cuidado adicional dirigido a quem necessitasse de diferentes acompanhamentos num momento de adoecimento e fragilidade, suscita questionamentos acerca da abordagem feita por diferentes racionalidades, sobretudo no que diz respeito aos seus resultados efetivos para os usuários, bem como no plano das relações entre os profissionais. Isto porque tal produto (ou seja, a ação interdisciplinar), para ser alcançado, demanda um trabalho de parceria entre médicos e profissionais "psi”, implicando um diálogo entre campos disciplinares distintos que se daria na interface entre o saber médico e o saber "psi". Ao darmos início à pesquisa, questionávamos a efetiva integração de diferentes profissionais com perspectivas epistemológicas e, não raro, políticas, tão distintas.

Nossas questões se fundamentam na consideração do modelo hegemônico da medicina moderna, conhecido por sua racionalidade de cunho objetivante. Segundo Camargo (1990, p. 58), o olhar do médico em direção ao paciente está mesclado por suas representações relativas ao seu universo e protegidas pelo "escudo da racionalidade científica". Na mesma direção, Clavreul (1983, p. 121) acrescenta que "o saber médico é um saber sobre a doença, não sobre o homem, o qual só interessa ao médico enquanto terreno onde a doença evolui”. Dessa maneira, suas formas de agir estão referenciadas a conceitos como saúde, doença e tratamento, alimentadas pelo processo formal de ensinoaprendizagem, permitindo à Medicina alçar o estatuto de ciência. Isto porque, nesse domínio, romper com todo e qualquer sentido subjetivo e apoiar-se em concepções metodológicas objetivou conferir rigor às descobertas e, desta forma, fugir do ostracismo e de suas incertezas.

Com o aparecimento da Anatomia Patológica, na qual as lesões dos órgãos ganham prestígio entre as "verdades científicas", confirma-se a autoridade do discurso biológico sobre os demais, reduzindo a complexidade do objeto de estudo. Em seu desenvolvimento como ciência, a Medicina fez com que seu objeto, a "vida", fosse se distanciando, cada vez mais, do sujeito que encarna seu corpo, levando-nos a constatar um paradoxo nos conceitos que regem essa disciplina, bem como entre seu saber e sua prática. Como nos diz Camargo 
(1990), a Medicina, ao incorporar a doença como expressão de lesão celular, torna-se uma ciência das doenças e afasta-se de sua "arte de curar". Por esse viés, o paradigma da ciência moderna que sustenta a Medicina contemporânea tem-se mostrado insuficiente para alcançar toda a complexidade que circunda o mundo real e sensível e, nele, o fenômeno multidimensional que se denomina saúde (LUZ, 2003) e, em particular, Saúde Mental.

Assim, entendemos como um objeto de interesse o resgate das percepções médicas sobre o serviço de Saúde Mental e o segmento que nele atua, visando a não apenas compreender o sentido dos pedidos de parecer e de atendimento, e do quanto os profissionais "psi" estariam efetivamente interagindo com a prática médica tradicional, como também oferecer subsídios para formulações em direção ao aperfeiçoamento dessas ações específicas. $\mathrm{O}$ estudo nos remete, ainda, à consideração dos aspectos subjetivos do paciente no bojo dos atendimentos realizados, tanto por médicos quanto por profissionais "psi", interessando-nos ressaltar, dentre eles, percepções de profissionais médicos acerca do que constitui "um problema de Saúde Mental" ou sobre as demandas subjetivas de seus pacientes, bem como sua ressonância na categoria médica.

\section{Percurso metodológico}

Nosso estudo desenvolveu-se, conforme já apontado, junto a profissionais médicos de uma unidade hospitalar, no município do Rio de Janeiro, fundamentando-se na abordagem qualitativa de investigação em saúde, numa perspectiva crítico-interpretativa. Tal opção visa à apreensão do significado do fenômeno sob estudo, a partir da ótica dos atores envolvidos, estabelecendo uma aproximação com a subjetividade, considerando-a em relação à materialidade a que se vincula. Para fins de nossa pesquisa, utilizamos como compreensão do termo subjetividade a definição de Guattari, quando estabelece que ela pode se configurar em um estatuto individualizante ou coletivo, sendo este último mais abrangente para as questões de saúde. Desse modo, podemos situá-la como uma multiplicidade que se desenvolve para além do indivíduo, onde intensidades pré-verbais interagem no socius, "derivando de uma lógica dos afetos mais do que uma lógica de conjuntos bem-circunscritos" (GUATTARI,1992, p. 19).

A unidade hospitalar da pesquisa é referência, em emergência, para as especialidades de Ortopedia e Cirurgia Geral. Conta com 147 leitos, distribuídos 
pelas diferentes enfermarias, como: Clínica Médica, Pediatria, Ortopedia, Cirurgia Geral, Unidade Intensiva, Centro de Tratamento Intensivo, além da Grande Emergência. A equipe de Saúde Mental atende a todas as solicitações, de pedidos de parecer e/ou acompanhamento psicológico no leito, pelos diferentes espaços do hospital até a alta do paciente, incluindo atendimento e orientação aos familiares, e interconsultas, com profissionais envolvidos nos casos.

Conforme já assinalado, nossa pesquisa se configura nos moldes de um estudo de caso, na medida em que se refere a uma análise profunda e extensa de uma situação particular, possibilitando-nos dialogar de forma densa e rigorosa com processos mais amplos do atual sistema de saúde do qual esse espaço é parte constitutiva.

Para visualizarmos o plano analítico estabelecemos, na fase exploratória da pesquisa, um diálogo entre as dimensões qualitativa e quantitativa: partimos de um estudo de demanda da clientela do serviço de Saúde Mental, em um intervalo de seis meses, o que nos levou ao total de 2.143 registros, configurando um eixo marcante, inicial, do trabalho de campo. Os dados quantitativos foram processados no programa Access, permitindo-nos uma aproximação com o endereçamento de pacientes à Saúde Mental, etapa em que pudemos traçar o perfil de nossa clientela e visualizar de onde partiam as solicitações para a equipe de Saúde Mental, assim como identificar as categorias profissionais que o faziam, bem como clarificar o tipo de paciente que os médicos lhe encaminhavam. Essa dimensão não será aqui examinada; cabe-nos apenas ressaltar que desta etapa derivou a amostra teórica (TESCH, 1990), indicandonos os critérios para seleção dos informantes: a amostra constituiu-se por médicos que, no momento do estudo, tinham pelo menos dois anos de atividade na unidade hospitalar, propiciando uma relação mais estreita com o serviço investigado e com suas estratégias de ação. Em adição, o profissional médico já deveria ter solicitado parecer e/ou encaminhado pacientes para a equipe "psi". Este último critério também foi considerado em constraste, conforme apontado adiante.

No que concerne à suficiência da amostra no enfoque aqui adotado, esta foi validada pelo fato de permitir certa reincidência das informações capaz de esclarecer de modo consistente as questões que configuram o objeto, permitindo o aprofundamento da compreensão pretendida. Além disso, contemplamos a necessária diversidade, de modo a possibilitar o aprofundamento da compreensão, não somente pelas semelhanças, mas igualmente pelo contraste das diferenças. Isso nos levou a considerar oportuno incluir, além dos critérios 
acima, informantes procedentes de locais dos quais quase não se originaram chamadas para a Saúde Mental, contraponto que permitiu um enriquecimento da interpretação.

Ao nos interessarmos em focalizar os profissionais médicos quanto às reflexões de seu campo de trabalho e em sua relação com os profissionais "psi", buscamos recuperar uma gama de significados, capazes de nos revelar, através da interpretação dos sentidos produzidos, o que perpassava aquele segmento médico, em relação às questões norteadoras do estudo.

Estamos cientes de que, ao "alçar vôo" em direção às interpretações e busca de sentido para o material empírico desta pesquisa, os aspectos subjetivos e nossa condição humana ante um objeto igualmente humano nos restringiriam nos limites do olhar e do sentir (BOSI; MERCADO, 2004). Nesse contexto se impõe ao pesquisador suportar o deslizamento polissêmico dos significantes e trabalhar "exaustivamente" com todos os significados emergentes, no caminho da compreensão de um sentido que contemple, na medida do possível, suas indagações. Isto porque nessa modalidade de pesquisa há uma questão ontológica que imbrica "sujeito e objeto em um movimento intersubjetivo", fazendo o pesquisador entrar em contato com a experiência vivida pelo sujeito pesquisado, onde um pólo decodifica sua experiência na relação com o outro. Acreditamos que tal relação não deve ser negada ou abstraída, mas considerada como inerente à pesquisa social de cunho qualitativo (BOSI; MERCADO, 2004).

Alicerçado nas premissas aqui resumidas, o material empírico de nosso estudo se constituiu pelas falas dos entrevistados, bem como por gestos e outras expressões que se mostraram úteis para substantivar ou adjetivar a comunicação dentro de um contexto "analógico" ou "digital" (WATZLAWICKY; BEAVIN; JACKSON, 1999).

Realizamos, ao todo, 12 entrevistas não-diretivas (KANDEL, 1987) com médicos, alguns deles inseridos em sua prática, tanto nas emergências quanto nas enfermarias. Elegemos a entrevista em profundidade como técnica de apreensão dos dados empíricos, tomando como base "perguntas disparadoras". O conteúdo do material, gravado após o consentimento dos informantes, foi transcrito em momento posterior por uma das pesquisadoras. Processado o material, teve início o exercício hermenêutico, entendido como arte e técnica (SCHLEIERMACHER, 2003), sustentado na vertente históricocrítca (GADAMER, 1997; ROHDEN, 2003). 
O material discursivo foi organizado em torno de um eixo composto por três "temas centrais", desdobrados, por sua vez, em distintas dimensões. Estes foram os elementos norteadores do diálogo empreendido com o referencial teórico.

Como recurso de exposição dos temas e principais dimensões da rede interpretativa, utilizamos no corpo deste texto categorias que emergiram no discurso dos informantes, cuja objetividade semântica demonstrou especial potência evocativa e, ao mesmo tempo, representatividade, em termos semânticos. Tais expressões se fazem acompanhar por nossa interpretação após o uso de um sinal de pontuação, conforme segue:

\section{Tema 1: “A gente está tratando humano como boi na Saúde Pública": o cotidiano da prática;}

Dimensões: "O médico é o nervo exposto do sistema": as sobrecargas e as queixas;

"A regra do jogo são dois minutos para cada paciente": o tempo não pára.

\section{Tema 2: "Saúde Mental": conceitos, possibilidades e impedimentos.}

Dimensões: "Vocês despertam umas visões humanas que a gente não tem": o cuidado;

"Se o cirurgião não tiver um bom mecanismo de defesa, ele afunda também": a angústia;

"Todas as especialidades são complemento de um só objetivo, o doente": a aventura interdisciplinar.

\section{Tema 3: “A escuta e o olhar": instrumentos de uma atenção diferenciada.}

Embora se reconheça a interpenetração dos temas na tessitura do que aqui se considera rede interpretativa, no exercício hermenêutico desenvolvido neste artigo exploramos os dois primeiros. Neles abordamos, respectivamente, percepções referentes ao cotidiano da prática e, na seqüência, as concepções sobre o objeto e o campo da Saúde Mental. A questão relacional, dialógica, conteúdo do terceiro tema, desencadeou um novo percurso em campo, ainda em desenvolvimento, que será em momento oportuno comunicado. A discussão que se segue busca, em síntese, apresentar o diálogo estabelecido com alguns 
elementos do universo semântico que o estudo permitiu recuperar, tendo como caminho analítico a interlocução com o plano teórico-conceitual.

\section{Percorrendo a rede interpretativa}

\section{“A gente está tratando humano como boi na Saúde Pública”: o cotidiano da prática}

O primeiro tema surgiu espontaneamente e de forma muito recorrente nos depoimentos dos médicos, o que nos permitiu desdobrá-lo em dimensões intrínsecas às vivências dos profissionais acerca do cotidiano da sua prática na unidade hospitalar focalizada nesta pesquisa. Apesar de este tema não estar diretamente relacionado às vivências dos profissionais em relação à Saúde Mental, consideramos relevante sua inserção, na medida em que representou uma necessidade espontânea, dos entrevistados, de falarem da prática hospitalar e do que consideram difícil de administrar frente a várias questões perpassadas pela própria categoria na saúde. Assim, duas foram as principais dimensões referentes ao tema: "O médico é o nervo exposto do sistema": as sobrecargas e as queixas; e "A regra do jogo é dois minutos para cada paciente": o tempo não pára.

A primeira dimensão - "O médico é o nervo exposto do sistema": as sobrecargas e as queixas - sugere que as ações em saúde não estão representando uma resposta social adequada às concepções do paradigma da Reforma Sanitária, que defende a integração entre os serviços e a intersetorialidade como pontos importantes para a configuração da rede de assistência (LUZ, 2003 e 1998). A organização do sistema de saúde se apresenta, ainda, atravessada pelo dilema qualidade versus quantidade:

A sobrecarga de stress é muito grande [...] são trezentos atendimentos por dia, a gente é pressionado [...] a falência do serviço público é grande [...] e médico é o nervo exposto do sistema. Aí tratamos ser humano como lixo: falta material, falta maca, falta leito, falta medicação. Além do déficit muito grande, existe a frieza das pessoas [...]. O melhor médico é o que dá alta para todos os pacientes, não importa se o paciente vai voltar amanhã e vai morrer, ou vai morrer em casa [...]. Alguém um dia vai entender que não está dando mais. Não é continuar nessa ciranda, nesse ciclo, porque fica tudo errado. A gente está tratando humano como boi na saúde pública. (Entrevista 1). 
Depreendemos nessa fala, que ressoa em muitas outras, uma catarse que nos permite destacar o evidente sentimento de menos-valia e sofrimento psíquico, prejudicando sensivelmente a autopercepção da categoria médica e (por que não dizer?) acentuando suas críticas em relação à sua própria atuação profissional que, entretanto, não se desdobra em reinvindicação, permanecendo no plano da "queixa" (BOBBIO, 1992). Fazemos, ainda, referência à ênfase na reprodução do instituído, analisada por Guilhon (1978), caracterizando a perpetuação de um certo cotidiano, vivenciado como uma relação "natural" que tende a se repetir sempre de uma mesma forma. Parece-nos, pelos relatos, que a ação médica ainda não se vê como instituída, ou seja, como a que produz essa “ordem natural”, incapaz de impedir os desvios da própria prática.

Transparece nesses depoimentos o sentimento que o próprio profissional tem sobre a postura que foi se incorporando ao ritual de atendimento à população, principalmente quando ele se encontra na pequena emergência do espaço hospitalar estudado, que tem um enorme contingente de usuários à espera de ajuda. De outro modo, podemos interpretar esse material como o incômodo na percepção da prática, ao mesmo tempo que restitui o lado ético do trabalho médico, devendo este se ligar ao cuidado para com o outro (GUILHON, 1978; FREIRE, 2002).

\section{[..] .quantas vezes eu já abordei o paciente mais friamente e depois no meio da consulta eu penso: "Cara, você é um canalha! Como você pode tratar um ser humano desse jeito?” Ou então, você já chega para o paciente com uma carga de agressividade e, às vezes, ele te dá uma resposta e se mostra frágil e você se sente o agressor. Aconteceu isso hoje comigo. Está entendendo [...] a sobrecarga de stress é muito grande [...] há muita pressão. (Entrevista 1).}

Esse material não pode ser analisado de forma dissociada do contexto sócio-histórico que molda nosso sistema de saúde, pois esse pano de fundo se insinua, silenciosamente, no cotidiano de nossos atores sociais, situando-os em relações de poder, como um círculo vicioso que não iremos aqui explorar, mas que cabe mais uma vez reconhecer (CAMARGO; PINHEIRO, 2000).

A segunda dimensão deste primeiro tema - “A regra do jogo são dois minutos para cada paciente": o tempo não pára - refere-se à variável tempo interferindo nos atendimentos, como um plano atravessado por uma intrincada dinâmica de relações entre inúmeros atores. O exercício hermenêutico empreendido revelou a polissemia da categoria tempo no espaço da assistência, 
revelando seus múltiplos sentidos que desvelam, ainda, nítidas diferenças na abordagem aos usuários, constrastando-se emergências e enfermarias.

Nas emergências revela-se o tempo oficial a serviço da produtividade esperada e mesmo necessária nessa modalidade de assistência, que impele o médico a "correr" em seus atendimentos, ocasionando pouca disponibilidade na consulta para um aprofundamento de questões referentes ao adoecimento, bem como ao vínculo inerente à relação profissional-usuário:

[...] não temos tempo hábil para ouvir as queixas mais importantes, fica faltando esse outro lado [...]. Você sabe a importância da palavra, a importância das pessoas serem ouvidas, vêm aqui para serem ouvidas em seu desabafo [...]. Mas se eu demorar, eu negligencio o bom andamento do trabalho. (Entrevista 4).

[...] você está sempre correndo contra o tempo, a fila está sempre grande [...] a gente pega num serviço de emergência umas duzentas pessoas [...] se você começa a falar muito, o cara lá de fora vai começar a reclamar que está demorando muito. (Entrevista 2).

A categoria tempo também emergiu como "solução de descarte", ou seja, como solução rápida, visando a dar respostas quase sem contato:

[...] anamnese de 40 minutos é contra o sistema, a regra do jogo é dois minutos para cada paciente [...]. Aqui, tenho que seguir o que me pedem [...]. É o preço da fila começar e o tumulto começar e quebrar tudo, você sabe; se o doente não abrir a boca ele não atrapalha meu raciocínio [...] (Entrevista 6).

[...] por causa do ambiente de pouco tempo que a gente tem, a gente tem que correr o tempo todo, explica tudo, vira as costas e vai embora. (Entrevista 9).

Essa forma quase automática de lidar com o usuário pode resultar na indiferença e no pouco cuidado (BALINT, 1998). Como contraponto a essa postura, reitera-se na fala abaixo uma crítica ao "corre-corre" das emergências e uma frustração pessoal implícita, significando o desejo, já aqui aludido, de compreender o que se passa com o usuário e de assisti-lo, aspecto que faz interface com o tema seguinte, relativo ao lugar da Saúde Mental e dos profissionais "psi": 
[...] aquela coisa de poder conversar, tentar acalmar, orientar e avaliar se alguma coisa mais profunda precisa de um tratamento ou se é só uma emoção [...]. Isso a gente não tem tempo para fazer [...]. A doença do serviço público é dar alta, alta, alta; o melhor médico é o que "limpa" a grande emergência; não importa se o paciente vai voltar amanhã ou se vai morrer em casa [...]. Então, prá que tratar? [...] Medicação vai fazer outro efeito [...]. Essas pessoas chegam para a gente [...]. Acho que eles querem mesmo é que alguém se importe com eles e o se importar é ouvir, dividir, aconselhar, falar [...] e isso a gente não pode fazer porque não tem tempo [...] (Entrevista 1).

Encontramos em Schraiber (1993) uma compreensão que coincide com o conteúdo das falas acima, quando ela nos diz que, com a ampliação dos serviços de pronto-socorro, houve uma modificação no paradigma da disponibilidade plena do médico. Quando os informantes se referem ao usuário nas "enfermarias", o tempo se polariza: de um lado, traz a possibilidade da inclusão da subjetividade do usuário, como no exemplo abaixo:

[...] eu procuro ser carinhoso com o paciente, mesmo no escassíssimo tempo que eu tenho. Cirurgião tem muito pouco tempo para passar com o paciente. Você precisa de tempo para conhecer uma pessoa [...]. O instrumento de qualquer relacionamento é tempo, de você poder conversar, de você poder segurar na mão. (Entrevista 9).

Por outro lado, o tempo nas enfermarias mostra a mesma dificuldade encontrada nas emergências, imprimindo pressa aos atendimentos. Associado a ele, surge a categoria "paciência" fechando um círculo, onde uma retroalimenta a outra.

[...] por excesso de pacientes a gente não tem esse feeling de ter um pouquinho mais de paciência [...] (Entrevista 11).

[...] aqui eu passei por determinados problemas que, na realidade, cabia só você sentar um pouquinho com o familiar e falar meia dúzia de palavras para eles. (Entrevista 13).

Analisando esta dimensão como um todo, podemos inferir que o tempo não é uniforme pelos diferentes espaços do hospital, sendo percebido pelos médicos como algo exterior e não interior, não lhe pertencendo e sendo determinado pela forma como a assistência deve operar, conforme a organização do trabalho vis- 
à-vis as demandas da população. De outro modo percebemos, em alguns, a dificuldade de uma atenção integral ao paciente, englobando os aspectos intrínsecos à subjetividade, pela falta de tempo e, de certo modo, de paciência.

\section{"Saúde Mental": conceitos, possibilidades e impedimentos}

Neste segundo tema, nosso foco contempla o objeto de estudo propriamente dito, abrangendo: a inter-relação físico e psíquico, ou seja, as percepções dos informantes sobre o que seja Saúde Mental e os problemas que os levam a solicitar um parecer; as intervenções referentes ao serviço de Saúde Mental; e a relação entre o saber médico e o saber "psi”".

Na primeira dimensão - "Vocês despertam umas visões humanas que a gente não tem”: o cuidado - ressaltamos, de início, o lugar das emoções, sendo, por um lado, mencionadas pelos nossos informantes como interferente nas queixas físicas:

[...] Se você abordar o emocional você vai resolver $40 \%$ da doença [...] já aconteceu isso comigo, de ter paciência, de poder conversar, da pessoa chegar chorando e sair rindo [...] (Entrevista 1).

[...] 90\% dos casos que a gente resolve é ouvindo a pessoa. (Entrevista 2).

Essas falas encontram ressonância em Schraiber (1993), quando, indo ao encontro de muitos outros autores, diz que a doença não é a única explicação para a realidade do doente. De outro lado, as falas revelam o reconhecimento de que um trauma ou um ato cometido pelo usuário impelido por seu estado emocional, trazendo prejuízos ao seu corpo, nem sempre é bem aceito pela categoria médica, que muitas vezes demonstra irritação, como se estivesse perdendo tempo ou fugindo da objetividade que sustenta o modelo formador ainda hegemônico, como marca de cientificidade (PÓVOA, 2002).

[...] tem muita gente da área médica que [...] se uma pessoa tomar chumbinho, fica tripudiando [...] mas isso é uma doença. Ela não tomou aquilo para [...] claro, chamar atenção; é uma doença. Ninguém faz isso para vir aqui tomar lavagem, ser furado. (Entrevista 2).

Ainda nesta dimensão, apreendemos conceituações e percepções sobre o tema da saúde mental na visão dos médicos. Resgatamos inicialmente a surpresa ante a atuação de uma equipe de Saúde Mental no hospital: 
[...] esse é o único hospital que eu trabalho, que eu tenho a presença da Saúde Mental à mão, de forma diferenciada [...]. Aqui é uma novidade; o que torna nosso trabalho mais agradável. (Entrevista 5).

[...] eu já passei por alguns hospitais e este é o primeiro que vejo uma equipe assim, diariamente a gente tem aqui um profissional, sempre presente. (Entrevista 10).

Por meio desses depoimentos, constatamos que o modelo implantado de Saúde Mental foi percebido pelos informantes, no dia-a-dia, da prática, associandose à percepção de um auxílio imediato possibilitado pela presença constante da equipe. De modo geral, os informantes sinalizaram conceituações pertinentes ao termo "saúde mental”, interseccionando nas falas diferentes planos: físico, psíquico e, às vezes, espiritual, realçando-se a afetividade como ponto importante na vida das pessoas. De outro lado, pontuam "saúde mental" como dando um respaldo ao atendimento efetuado por eles, "acrescentando", "informando", "trocando".

Interessou-nos investigar a percepção desse segmento médico, quanto ao papel que consideram relevante para essa modalidade de atendimento. Em suas falas verificamos que existe certa recorrência no material explicitado, em particular no que se refere à distinção do termo/conceito "suporte" como representativo das atividades "psi" no hospital:

[...] saúde mental dá o suporte, que é o conhecimento dessa área que o clínico não aprofundou [...] e muitas vezes vocês acabam nos ajudando [...] Vocês despertam umas visões humanas que a gente não tem. (Entrevista 3).

Alguns informantes mencionam o "suporte" tanto para os usuários, familiares, quanto para eles próprios, os médicos:

[...] suporte para as crianças e mães, no sentido de enfrentar a doença. (Entrevista 7).

[...] suporte à clínica médica: quando o paciente tem um desequilíbrio voltado à Saúde Mental, uma crise nervosa, uma crise hipertensiva que você não consegue resolver só com medicamentos utilizados na prática comum. (Entrevista 4).

[...] suporte psicológico ao paciente internado que compreende o acompanhamento, a avaliação, a visita diária, tudo isso [...] (Entrevista 1). 
Outros incorporam a necessidade de "suporte" nos momentos em que encontram dificuldades com um óbito, com familiares, com usuários em circunstâncias que os deixam paralisados ou sem saber o que vão fazer. Isso denota a desumanização e o despreparo característicos da formação médica para lidar com o sofrimento, acolher e, mesmo, oferecer o suporte que tanto mencionam (CAMARGO, 1998):

[...] o relacionamento com a Saúde Mental é uma forma de socorro; a gente pede socorro à especialidade [...]. O paciente se torna agressivo, nãocooperativo, busca outros subterfúgios, existe uma quebra no relacionamento entre paciente e profissional, [...] alguém tem que entrar nesse circuito para refazer a harmonia [...] reparar o erro que existiu entre paciente e staff. (Entrevista 11).

[...] a Saúde Mental vai quebrando o gelo, chega, conversa, quando o paciente volta para mim já está mais liberto, já conversa, é outra abordagem. (Entrevista 2).

Outros ainda reconhecem que não usam a própria sensibilidade na compreensão do que se passa com o usuário:

[...] a gente não consegue ter a sensibilidade de tocar em determinado foco, em determinado aspecto com o paciente [...]. Para mim, vocês são um canal de informação que eu tenho sobre o paciente para eu tentar dar mais para ele [...] (Entrevista 9).

Percebemos, de modo geral, certa ambivalência nesses depoimentos, dada a interface entre o "suporte" para o usuário e o "suporte" para o profissional. Isso nos faz indagar se o profissional "psi" é percebido como facilitador da relação que os médicos desejam resolver e/ou descartar, apesar do êxito em inúmeras trocas interdisciplinares. Por esse viés, os discursos de dor e sofrimento não seriam ouvidos e a função médica seria medicar, como se tratar e conversar fossem aspectos independentes ou, mesmo, contraditórios (SCHRAIBER, 1993).

Avançando em nossa pesquisa, registramos o que os médicos percebem como casos pertinentes à Saúde Mental.

[...] bem abrangente: pacientes suicidas, dependentes químicos de um modo geral, em crises de abstinência, em crises por intoxicação por excesso de drogas, em quadros demenciais senis, ou seja, ansiosos, deprimidos, 
angustiados, com doenças crônicas, agudas, pacientes terminais, idosos, o traumatizado, o DNV, stress emocional. (Entrevistas 3, 4 e 9).

Entre alguns informantes, percebemos uma dificuldade em lidar com os aspectos emocionais na relação profissional-usuário, encaminhando-os, por esse motivo, para a Saúde Mental. Acreditamos que isso aconteça na medida em que a demanda dos usuários margeia o fenômeno da complexidade, no qual se cruzam várias questões de natureza social, econômica, política, psicológica e física (MORIN, 1996), cuja natureza desafia os médicos não apenas no que se refere ao tempo, como também em termos de competências e habilidades para enfrentá-las:

[...] quando a criança está muito grave e eu sinto que a mãe não percebe que aquela criança está grave; ela pode ir a óbito e a mãe não tem absoluta noção de nada. (Entrevista 7).

[...] quando o paciente não está bem com ele mesmo, não consegue transpor as barreiras, não consegue transpor o que ele está sentindo. Ele se torna arredio, fechado, a gente tenta falar [...]. Pacientes que fazem uso de medicação psicotrópica, às vezes, o paciente agressivo, pacientes alcoólatras, que é a maioria, que entra em abstinência. (Entrevista 2).

Encontramos ainda situações que apontam para outra funcionalidade, representando o descarte da relação: "[...] quando o paciente chora ou diz que brigou com a sogra eu chamo a Saúde Mental" (Entrevista 6).

A segunda dimensão - "Se o cirurgião não tiver um bom mecanismo de defesa, ele afunda também”, a angústia - reflete o segmento médico que poucos encaminhamentos fez aos profissionais "psi". Identifica-se nas falas uma objetividade acentuada, presente no discurso médico, marcado por uma des-subjetivação, operada no sujeito, embora o informante demonstre angústia ante a doença do usuário (CLAVREUL, 1983). Na prática prevalece o conflito onipotência versus impotência:

[...] não ver o doente como objeto, eu sempre falo isso; como só objeto de aprender. [...] O cirurgião fica um pouco frio para isso. Você abre e fala "coitado do doente, doente jovem, mas está com câncer" [...]. Eu acho que você não pode falar para o paciente no pós-operatório, de imediato o que ele tem, aos poucos ele vai tomando conhecimento do que tem, no ambulatório [...]. Porque quando ele fica sabendo, ele afunda. Mas se o cirurgião não 
tiver um mecanismo de defesa bom para isso, ele afunda também [...]. A maioria dos cirurgiões passa por cima disso. Na verdade, ele é frágil do mesmo jeito [...] (Entrevista 12).

Destacamos ainda a percepção que o informante tem do sofrimento do usuário, mas isso não é trabalhado na relação, realçando-se muito mais em seu discurso a preocupação com a intervenção técnica em um corpo anátomoclínico, consoante as representações da Biomedicina:

[...] a paciente falou para mim: "eu sei que eu estou com câncer [...] que eu vou para casa condenada, que eu vou para casa para morrer [...] Com certeza, vocês (da Saúde Mental) sabem falar melhor, sabem colocar melhor as coisas, mas o cirurgião é desse jeito [...]. É muita gente, ele quer ficar livre daquele problema, tirando aquele problema é outro que vai dormir naquele leito, aquele já foi, amanhã eu esqueço ele. Amanhã já estou operando outro." (Entrevista 12).

Na terceira dimensão deste segundo tema - "Todas as especialidades são complemento de um só objetivo, o doente": a aventura interdisciplinar - focalizamos as percepções da categoria acerca das possibilidades de trabalho multiprofissional e interdisciplinar entre os profissionais "psi” e os médicos, assim como convergências e divergências.

De início, cabe assinalar a dificuldade de os informantes conceituarem e diferenciarem o que seja um enfoque "multiprofissional" e "interdisciplinar": alguns consideram a mesma coisa, outros se equivocam na diferenciação, conforme ilustra esta fala:

[...] primeiro momento: cena do trauma, você foi para cima do doente sangrando, com uma fratura exposta, então você tem o médico da cirurgia geral, o médico do trauma, o ortopedista, o enfermeiro; o paciente depois foi internado, então você tem o médico da patologia específica que a gente conseguiu identificar no paciente, é cirurgia geral, ortopedia, ou os dois, uma enfermeira e uma psicóloga todos juntos; então, se ele tem uma lesão, enfim, no pescoço, na cabeça, entra a fonoaudióloga, se é um paciente debilitado, entra a nutricionista junto, isso eu entendo como multiprofissional, sei lá [...] ou é interdisciplinar? (Entrevista 9).

O conceito de multidisciplinaridade, segundo Nunes (1995), se refere a uma justaposição, sem haver, necessariamente, um trabalho de equipe e de 
coordenação. A interdisciplinaridade, por sua vez, é conceituada por Vasconcelos (1997) como sendo uma modalidade integradora do campo da Saúde Mental, com enriquecimento mútuo, com tendência à horizontalização das relações de poder entre os campos implicados. Apesar de considerarmos o trabalho interdisciplinar, um objetivo a ser instituído nas equipes de saúde, os achados apontam, em sua maioria, para um trabalho, se muito, multiprofissional. Mesmo assim, resgatamos percepções que endossam o trabalho interdisciplinar - melhor dizendo, "momentos interdisciplinares" -, afirmando, após o diálogo com os profissionais "psi”, mudanças na direção da assistência ou na própria postura do médico:

[...] modifica, porque eu entendo qual o paciente que eu tenho que dar mais atenção e qual a abordagem que preciso ter com ele: se eu preciso ser mais compreensivo, um pouco mais alto astral, se eu preciso dedicar mais tempo para ele, ir várias vezes vê-lo [...]. De todos esses aspectos que a gente está falando o que mais me faz mudar a conduta é quando vocês trazem alguma informação de que o paciente precisa de mais tempo comigo [...] (Entrevista 9).

[...] só me acrescentou [...] como médica, como pessoa. Tem médicos que tiveram a mesma noção do que eu, para várias coisas, e não mudaram seu ponto de vista [...]. Eu via com uma grande dificuldade a questão do suicida, eu não via com bons olhos [...] (Entrevista 3).

Outros informantes, no entanto, expressam alívio por terem profissionais "psi” “à mão" para cuidarem da parte psicológica, expressando muito mais um caráter paramédico (FREIDSON, 1978) no trabalho "psi” do que o que aqui se considera "interdisciplinar." Noutras palavras reafirma-se, em vários depoimentos, uma ambigüidade no que se refere a uma proposta interdisciplinar versus uma "hierarquização paraprofissional" (BOSI, 1996) ou interdisciplinaridade auxiliar (VASCONCELOS, 1997) no trabalho em saúde:

[...] até para resolver trabalhar com uma parte e deixar realmente a outra para a Saúde Mental. (Entrevista 3).

[...] meu papel aqui é o de clínico. Eu sou clínico, eu trato da parte física e dessa outra parte eu chamo a Saúde Mental. A gente fica mais relaxado sabendo que tem Saúde Mental. (Entrevista 2). 
Contudo, identificamos momentos que propiciam novas construções no plano conceitual, e, por conseguinte, práticas diferenciadas. É interessante observar que as trocas entre as especialidades, geralmente se dando de maneira informal, pelos corredores ou enfermarias, nem sempre não percebidas pelos médicos como um trabalho, ou seja, como uma interconsulta. Há, porém, um consenso de que as trocas entre profissionais possibilitam melhor preparação do usuário para enfrentar os momentos difíceis da hospitalização.

[...] é todo mundo agindo junto [...] todos juntos, nas visitas. O trabalho de um, sendo um pedaço do trabalho do outro. O trabalho não está completo se não tiver [...] é como se fosse uma colchinha de retalhos. (Entrevista 1).

[...] da minha parte de clínico, acho que tem que ter uma integração. Eu procuro compreender, eu leio as anotações, às vezes, eu não posso estar junto para fazer o atendimento, mas eu leio o que foi visto pela Saúde Mental. (Entrevista 2).

Embora haja disponibilidade dos profissionais para realizar um trabalho em equipe, muitos ainda receiam uma destituição de seu lugar, da hegemonia de seu saber, ratificando o que aponta a literatura (BOSI, 1996; LOYOLA, 1987; VASCONCELOS, 1997). Uma das dificuldades de se operacionalizar esse tipo de tarefa em grupo é o desejo de domínio de uma determinada categoria profissional sobre o funcionamento da equipe (FREIDSON, 1978; VASCONCELOS, 1997). Parece-nos que uma das condições para frutificar a idéia de interdisciplinaridade é a ausência de competição e do medo de o profissional médico ter suas orientações clínicas desviadas ou impedidas; ou ainda, seu desprezo por outras categorias, o que nos parece uma barreira cultural e política difícil de ser transposta:

[...] pessoas que são muito fechadas, acham que tem que ser o médico para tudo, inclusive tratam até com menosprezo. Acho que tem que ser mudado. Aqui já mudou muito, porque vocês assumiram o espaço de vocês, acho isso muito importante. (Entrevista 1).

A distância entre "saber médico" e "saber "psi"” surgiu no contexto das falas, denotando ora uma aproximação, ora um afastamento ou diferenciação na atuação ou na abordagem de cada categoria profissional:

[...] vocês, da Saúde Mental, fazem um trabalho mais meticuloso em termos de ouvir $[\ldots]$ conversam com o paciente sobre vários aspectos e, aos poucos, 
vocês descobrem que o paciente não entende nada do que ele tem [...]. Aí vou junto conversar com ele [...]. Nós, os cirurgiões da Ortopedia, somos muito mais objetivos do que técnicos [...]. Se a cirurgia tem um prognóstico bom, você é muito objetivo, tem um relacionamento distante, é técnico, pontual, cartesiano. (Entrevista 9).

[...] quando a gente precisa de um suporte medicamentoso, há necessidade do psiquiatra, mas quando há o serviço de recomendação e aconselhamento, o trabalho da psicóloga é o mais importante [...]. Até vou ser radical, eu acho que todos os pacientes que dão entrada na emergência deveriam ser abordados por vocês, pela psicologia [...] nem que seja uma só, a gente ter à mão, porque não é só o medicamento que ajuda e atua. Vocês vão também nos ajudar bastante. Há necessidade da presença maior de vocês do que do medicamento. (Entrevista 5).

Mesclando-se às falas acima, que apontam interações distintas, até mesmo instrumentais, subordinadas e parciais, a interdisciplinaridade também se insinua, conforme exemplifica a fala de um de nossos informantes que elegemos como fecho, apontando um processo que entendemos, ainda, como utopia a ser ou não construída, mas que no espaço investigado já se encontra, ao menos, delineada no plano do desejo.

[...] todas as especialidades são complemento de um objetivo só, o doente

[...]. Ninguém é mais ou menos, todas são importantes, parcela maior ou menor. Se fizer falta, o quebra-cabeça não fecha. (Entrevista 11).

\section{Considerações finais}

As interfaces entre saber médico e saber "psi", evidenciadas pelas percepções dos informantes, apontam a subjetividade como dimensão de relevância, tanto no que tange ao atendimento, quanto à própria subjetividade dos profissionais médicos no momento das entrevistas, deixando aflorar o afeto, a fragilidade e o sofrimento nas relações estabelecidas no cotidiano da prática médica.

De uma maneira geral, os resultados do estudo apontam uma heterogeneidade no que se refere às concepções dos informantes em relação a alguns temas: ora constatamos convergências, ora divergências que conferem complexidade ao objeto aqui explorado. 
No tocante à organização do trabalho na rede pública de serviços, nossos informantes destacam o tempo como variável fundamental no cotidiano dos atendimentos, tanto nas emergências quanto nas enfermarias. O tempo, nas emergências, apresenta-se como tendo múltiplos sentidos: interferindo na forma dos atendimentos para atender à demanda e à produtividade esperada; propiciando stress, pela insuficiência no cuidado e na atenção ao usuário; representando uma oportunidade de descarte da situação que se quer interromper e, finalmente, sendo imprescindível para um contato efetivo com os usuários. Nas enfermarias também registramos uma não-uniformidade dos informantes em relação ao tempo: para uns, o tempo é apontado como menos interferente; para outros informantes, o tempo permanece com a mesma conotação que nas emergências, revestido de pressa e impossibilitando o acesso às demandas subjetivas dos usuários.

Quando o médico faz a associação entre "tempo" e "paciência", surge como pano de fundo toda a sua angústia, diante da subjetividade lançada na relação profissional médico-usuário, demonstrando sua dificuldade em acolher esse tipo de demanda, que prefere direcionar aos profissionais "psi".

Desse modo, a qualidade da assistência não se revela determinada apenas pelo tempo, mas pela implicação do médico nas questões trazidas pelo usuário. As categorias tempo, paciência e afeto são aspectos que interferem na assistência e na maneira pela qual os médicos se posicionam diante da possibilidade de incluírem outras dimensões no processo de adoecimento, permitindo que a interdisciplinaridade ocorra, ou seja inviabilizada.

Quanto ao papel dos profissionais de Saúde Mental, a categoria discursiva "suporte" foi a mais recorrente, significando tanto o elo no auxílio da integração das dimensões presentes no usuário e seus familiares, que muitas vezes o médico não se sente em condições de atender, quanto um apoio ao próprio profissional, fragilizado por suas dificuldades pessoais e pelo stress gerado no cotidiano da assistência. Por outro lado, verificamos que o suporte pode ser uma forma de descarte, deixando para os profissionais "psi" o cuidado em relação ao psíquico. Ou ainda, uma restrição ao saber "psi”, considerandoo ora subalterno, "paramédico", ora uma ameaça à hegemonia do saber médico.

A idéia de interface entre as disciplinas "psi" e médica, almejada pelo modelo focalizado em nosso estudo, lança um olhar para a importância da subjetividade do usuário, revelando-se como um embrião na complementação dos saberes e na direção da melhoria da atenção, junto aos que solicitam a 
diminuição de seu sofrimento. Nas palavras de Castiel (1994, p. 25): "É preciso considerar que há produções originais de subjetividade, de acordo (ou em desacordo) com os variados elementos do contexto, de tal forma que podem intervir de modo cabal nos processos de adoecimento (e recuperação)".

\section{Referências}

ALMEIDA FILHO, N. Transdisciplinaridade e saúde coletica. Ciência \& Saúde Coletiva, v. 2, n. 1/2, 1997.

BALINT, M. O médico, seu paciente e a doença. Rio de Janeiro: Livraria Atheneu, 1998.

BOBBIO, N. A era dos direitos. Rio de Janeiro: Campus, 1992.

BOSI, M. L. M; MERCADO, F. J. Pesquisa qualitativa de serviços de saúde. Petrópolis: Vozes, 2004.

BOSI, M. L. M. Profissionalização e conhecimento: a nutrição em questão. São Paulo: Hucitec, 1996.

CAMARGO, J. K. R. (Ir)racionalidade médica: os paradoxos da clínica. 1990, 58 p. Dissertação (Mestrado) - Universidade do Estado do Rio de Janeiro, Rio de Janeiro, 1990.

. Medicina, médicos, doenças e terapêutica: exame crítico de alguns conceitos. Rio de Janeiro:UERJ/IMS, 1998. (Série Estudos de Saúde Coletiva, n. 170).

CAMARGO, J. K. R.; PINHEIRO, R. Modelos de atenção à saúde: demanda inventada ou oferta renovada?: algumas considerações sobre modelos de intervenção social em saúde. Physis, Rio de Janeiro, v. 10, n. 1, p. 101-119, 2000.

CASTIEL, L. D. O buraco e o avestruz: a singularidade do adoecer humano. Campinas: Papirus, 1994.

CLAVREUL, J. A ordem médica. São Paulo: Brasiliense, 1983.

CRESWELL, J. Research Design: Qualitative and Quantitative Approaches. London: Sage, 1994. 
FAGUNDES, H. M. ; LIBÉRIO, M. A. A reestruturação da assistência na Cidade do Rio de Janeiro: estratégias de construção e desconstrução. Saúde em Foco, Rio de Janeiro, ano 6, n. 16, p. 30-35, 1997.

FOUCAULT, M. O nascimento da clínica. Rio de Janeiro: ForenseUniversitária, 1998.

FREIDSON, E. La profesión médica: um estudio de sociologia del conocimento aplicada: versión espanhola. Barcelona: Ediciones Península, 1978.

FREIRE. O lugar do outro na modernidade tardia. São Paulo: Annablume, 2002.

GADAMER. Verdade e método. Petrópolis: Vozes, 1997.

GUATTARI, F. Caosmose. Um novo paradigma estético. Rio de Janeiro: Ed.34, 1992.

GUILHON, J. A. Metáforas da desordem. Rio de Janeiro: Paz e Terra, 1978. KANDEL, L. reflexões sobre o uso da entrevista, especialmente a não-diretiva, e sobre as pesquisas de opinião. In: THIOLLENT, M. Crítica metodológica, investigação social e enquete operária. São Paulo: Polis, 1987.

LOYOLA, M. C. D. Os dóceis corpos do hospital: as enfermeiras e o poder na estrutura hospitalar. Rio de Janeiro: EdUFRJ, 1987.

LUZ, M. T. Cultura contemporânea e medicinas alternativas: novos paradigmas em saúde no fim do século XX. Physis, Rio de Janeiro, v. 7, n. 1, p. 13-43, 1997.

. Natural, racional, social: ordem médica e racionalidade científica moderna. São Paulo: Campus, 1998.

. Novos saberes e práticas em saúde coletiva: estudos sobre racionalidades médicas e atividades corporais. São Paulo: Hucitec, 2003.

MÁXIMO, H. R. M. Saúde mental: um novo modelo em hospital de emergência. Saúde em Foco, Rio de Janeiro, ano 6, n. 16, p. 25-27, 1997.

MORIN, E. Epistemologia da complexidade. In: SCHNITMAN, D. F. Novos paradigmas, cultura e subjetividade. Porto Alegre: Artes Médicas, 1996.

NUNES, E. D. A questão da interdisciplinaridade no estudo da saúde coletiva e o papel das ciências sociais. In: CANESQUI, A. M. (Org.). Dilemas e desafios das ciências sociais na saúde coletiva. Rio de Janeiro: Hucitec, 1995. 
PÓVOA, E. C. Medicina baseada em evidências: critérios assistenciais. Rio de Janeiro: UERJ/IMS, 2002. (Série Estudos em Saúde Coletiva, n. 214).

ROHDEN, L. Hermenêutica filosófica. São Leopoldo: Unisinos, 2003.

SCHLEIERMACHER, F. D. E. Hermenêutica: arte e técnica da interpretação. 4. ed. Bragança Paulista: São Francisco, 2003.

SCHRAIBER, L. B. O médico e seu trabalho: limites da liberdade. São Paulo: Hucitec, 1993.

TESCH, R. Qualitative Research: Analysis, Type and Software Tools. New York: The Falmer Press, 1990.

VASCONCELOS, E. M. Desinstitucionalização e interdisciplinaridade em Saúde Mental. Cadernos IPUB. Rio de Janeiro, n. 7, p. 17-37,1997.

WATZLAWICKY, P.; BEAVIN, J. H. B.; JACKSON, D. D. Pragmática da comunicação humana. São Paulo: Cultrix, 1999.

\section{NOTAS}

- Mestre em Saúde Coletiva pelo Núcleo de Estudos em Saúde Coletiva da UFRJ; psicanalista; psicóloga no Hospital Municipal Lourenço Jorge/RJ; professora na Universidade Veiga de Almeida. Endereço eletrônico: hmaximo@ superig.com.br.

- Doutora em Saúde Pública; pesquisadora visitante na Universidade Federal do Ceará; professora

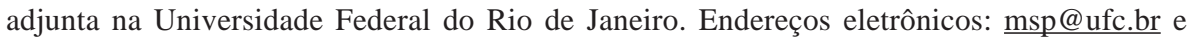
malubosi@nesc.ufrj.br.

${ }^{1}$ Este trabalho é fruto da dissertação de mestrado defendida pela primeira autora deste artigo, no NESC/UFRJ, em 2003, intitulada Saúde Mental num hospital público: interface com o saber médico, sob a orientação da segunda autora. 


\section{ABSTRACT}

\section{Mental Health in a Public Hospital: the Perspective of Medical Professionals of the City of Rio de Janeiro}

This study aims to understand the perceptions of the medical professionals at a public hospital, concerning the role of the Mental Health professionals, identifying simultaneously, the interfaces established between these two categories in the assistance enviroment. Therefore, we begin with the study on demand that characterizes the client assisted by mental health professionals, discussing the main demands required by the medical doctors in the different areas of the hospital unit. At the same time, we highlight the reasons of these indications. Based on this data, we have developed this study, founded on the quantitative approach as the methodological way, by choosing the non directive technique. The sample was composed of doctors from the group that refers patients to Mental Health professionals, and who had been in the hospital staff for at least two years. After the interviews, the analisys identified several themes, forming an interpretative network which was the basis for the hermeneutics exercise. The results of the study pointed to heterogeneous concepts of the informants about the role played by Mental Health within the hospital. In relation to the work organization, the variable time is a fundamental factor in the daily assistance. Differentiation between the psychological and the medical paradigms is observed. The practice finds it difficult to integrate both approaches.

Key words: Qualitative research; health professionals; Mental Health; health services; public health. 